10-28-2019

\title{
Oral Fungal Microbiota: To Thrush and Beyond
}

Dennis J. Baumgardner

Follow this and additional works at: https://aah.org/jpcrr

Part of the Bacterial Infections and Mycoses Commons, Environmental Public Health Commons, Family Medicine Commons, Fungi Commons, Infectious Disease Commons, and the Primary Care Commons

\section{Recommended Citation}

Baumgardner DJ. Oral fungal microbiota: to thrush and beyond. J Patient Cent Res Rev. 2019;6:252-61. doi: 10.17294/2330-0698.1705

Published quarterly by Midwest-based health system Advocate Aurora Health and indexed in PubMed Central, the Journal of Patient-Centered Research and Reviews (JPCRR) is an open access, peer-reviewed medical journal focused on disseminating scholarly works devoted to improving patient-centered care practices, health outcomes, and the patient experience. 


\title{
Oral Fungal Microbiota: To Thrush and Beyond
}

\author{
Dennis J. Baumgardner, MD \\ Department of Family Medicine, Aurora UW Medical Group, Aurora Health Care, Milwaukee, WI; Department of \\ Family Medicine and Community Health, University of Wisconsin School of Medicine and Public Health, Madison, WI; \\ Center for Urban Population Health, Milwaukee, WI
}

\begin{abstract}
The oral microbiota is complex, multikingdom, interactive, and involves extensive biofilm formation. While dominated by bacteria, Candida is a frequent member of this microbiota; however, several other potentially pathogenic fungi (among around 100 identified species) appear to reside in some individuals, including Cryptococcus, Aspergillus, and Fusarium. Oral candidiasis may manifest as a variety of disease entities in normal hosts and in the immunocompromised. These include pseudomembranous candidiasis (thrush), hyperplastic or atrophic (denture) candidiasis, linear gingival erythema, median rhomboid glossitis, and angular cheilitis. The purpose of this review is to describe the oral fungal microbiota (ie, oral mycobiota), common mouth diseases caused by its members, predisposing factors and treatment, and the potential for causing disseminated disease like their bacterial counterparts. (J Patient Cent Res Rev. 2019;6:252-261.)
\end{abstract}

Keywords mycobiome; candidiasis, oral; mouth disease; mycoses; fungi; Cryptococcus; Candida

\section{ILLUSTRATIVE CASE}

A 40-year-old generally healthy, nondiabetic, nonimmunocompromised man presented after having awoken with a very bad taste in his mouth. He also had noticed multiple white spots and some irritation on his upper palate. He had very recently and simultaneously been started on an inhaled steroid (triamcinolone acetonide inhalation aerosol) and began using a rubber over-the-counter mouth guard for treatment of nocturnal bruxism. This mouth guard occluded much of the upper palate and was noted to contain white spots on the contacting surface. Importantly, symptoms occurred despite rinsing his mouth following steroid inhalation.

Physical examination was unremarkable except for numerous small white plaques and some mild erythema of his upper palate, with similar but lesser lesions on his posterior tongue and oropharynx. Oral

Correspondence: Dennis J. Baumgardner, MD, Aurora Sinai Medical Center, 1020 N. 12th Street, \#4180, Milwaukee, WI 53233 (dennis.baumgardner@aurora.org) candidiasis (thrush) was diagnosed. The mouth guard was discontinued, and he was treated with clotrimazole troches. Signs and symptoms resolved over the next 2 days and did not recur.

\section{INTRODUCTION}

The microbiota of the human mouth is considered the second most complex, after the colon, and exhibits more diversity than the skin and other mucosal sites. ${ }^{1-3}$ This oral microbiota is comprised of complex, interactive communities of microorganisms and nutrients, predominantly bacteria, on oral cavity surfaces in biofilms. ${ }^{1,2,-6}$ These intricate and interactive biofilms may modulate the immune system and protect involved species from environmental insults. ${ }^{4-6}$ Some biofilm properties may actually improve or preserve oral health and defend against potential invading pathogens; others may increase virulence of potentially harmful microorganisms and decrease the effects of antimicrobial agents..$^{5-7}$

Microbiota are affected by a number of local and systemic factors, including heritable and other individual factors, diet, general and oral health, influx of new microorganisms (saliva exchanges with 
family members and other contacts, beginning in infancy), teeth brushing, dentures, dental procedures and appliances, mouthwashes, medications, and other agents. ${ }^{1,4,6,8-11}$ Nearly 800 microbial species have been identified in the oral cavity thus far. ${ }^{1,212,13}$ Most are bacteria; however, fungi also are present, in addition to archaea, protozoa, and bacteriophages. ${ }^{1-5,14,15}$

Most disease caused by members of the oral microbiota is bacterial. These mouth disorders - along with oral tumors, recurrent aphthous stomatitis, and possibly Behcet's disease - may be associated with disturbances of microbial biofilms/community members (dysbiosis) ${ }^{1}$ and "alterations of the homeostatic balance between the host and resident microbes." ${ }^{10}$ Local oral bacteriamediated diseases include dental caries (complex interactions of acid producing oral bacteria and fermentable carbohydrates), endodontic infections (progression of dental caries resulting in invasion of the pulp), gingivitis (reversible inflammatory disease of the gums caused by bacterial plaque formation at the gingival margin) and periodontitis (irreversible destructive progression of gingivitis). ${ }^{1,46,10,16}$ The oral cavity is the gateway to the gastrointestinal and lower respiratory tracts. ${ }^{9,15}$ In addition, potentially invasive microorganisms may enter the bloodstream from the mouth via tissue breakdown from oral disease or simply flossing one's teeth. ${ }^{4}$ Bacterial microbiota have been associated with a number of organ-specific or generalized infections due to spread of potentially pathogenic organisms from the oral cavity to the particular sites. ${ }^{4}$ These include more classic infectious entities such as aspiration pneumonia, ${ }^{17}$ abscesses, and bloodstream infections. ${ }^{4}$ Additional reports suggest possible etiologic roles of oral bacterial microbiota in remote tumors, cardiovascular disease, diabetes, rheumatoid arthritis and Alzheimer's disease. , $^{1,17-19}$

As oral bacteria have been well described, the purpose of this review is to describe the fungal microbiota (mycobiota) of the mouth, common mouth diseases caused by its members, and the potential for causing remote disease like their bacterial counterparts.

\section{MEMBERS OF THE ORAL MYCOBIOME Initial Colonization}

Initial microbial colonization of the infant gastrointestinal tract, including the mouth, differs according to vaginal birth versus cesarean section (fewer microorganisms of maternal origin), breastfeeding versus formula feeding, perinatal antibiotics, and other factors. ${ }^{10,16,20,21}$ Presumably, the healthiest infant gastrointestinal, and by extension oral, microbiota results from a combination of vaginal delivery, breastfeeding, and lack of exposure to antibiotics and other perinatal microbiota-modifying substances. ${ }^{21}$

The fungal genus studied most regarding colonization of the infant gastrointestinal tract, including the mouth, is Candida, a normal member of the vaginal mycobiota. ${ }^{20}$ C. albicans has been shown in vitro to influence the bacterial makeup of early oral biofilms, specifically favoring the presence of obligate anerobes. ${ }^{22}$ In a study of 100 Swedish infants, oral colonization with Candida species occurred in 12\% of 4-week-old babies, and levels remained stable at intervals up to 12 months. ${ }^{23}$ Infants with a furry pet at home had a lower frequency of Candida at 3 months, and all but a single colonized infant had older siblings at 12 months of age. ${ }^{23}$ Candidal colonization increases with age. ${ }^{4}$

In addition to Candida, several other species including (presumably commensal) Saccharomyces, Cryptococcus, Aspergillus, Malassezia, and Cladosporium have been demonstrated with molecular techniques in fecal samples of very-low-birthweight infants and children under 2 years of age. ${ }^{20}$ Little is otherwise known regarding oral colonization by fungi in children. In one study of Chinese children, 28 of $60(46.7 \%)$ subjects 9 years old or younger had oral yeasts recovered, including 15 Candida species, 7 unidentified yeasts, and 6 "other species," while 13\% of 550 subjects 10-19 years old grew oral yeasts, predominantly Candida. ${ }^{24}$

\section{Culture-Based Studies}

Approximately 100 fungal species have been identified from the human mouth, most of them not cultivatable. ${ }^{5}$ In a recent culture-based study of 40 healthy young student adults from a single dental school in Portugal, 68\% of subjects harbored Candida species in their oral cavity. ${ }^{9}$ This study, which used kit-based manual identification of yeasts and molecular diagnostics for molds, also revealed that most subjects harbored Rhodotorula, Penicillium, Aspergillus, and Cladosporium species in their mouths. A minority of subjects harbored Trichoderma, Scedosporium, Alternaria, and Rhizopus fungal species in the oral cavity. ${ }^{9}$ The authors noted 
that the filamentous fungi (all listed species except Candida and Rhodotorula) are mostly very common environmental molds and frequently found in nasal mucosa. They also documented intraindividual stability but high interindividual variability over time. ${ }^{9}$

Recent culture-based studies of middle-aged and older adults yield similar findings. Wang et al included all age groups and used sequence information from the internal transcribed spacer regions of the ribosomal RNA gene cluster to identify yeasts recovered from the oral cavity in 415 of 1799 (23.1\%) community-dwelling and hospitalized subjects tested. ${ }^{24}$ Of recovered yeasts, 298 of 415 (71.8\%) were C. albicans, C. glabrata, $C$. parapsilosis, or C. tropicalis species. Lesser recovered species include Kodamaea ohmeri, other Candida species, Trichosporon species, Cladosporium, Pichia, Rhodotorula, S. cerevisiae, and rare other species such as $C$. neoformans var. neoformans. This study found that gender and ethnic background of subjects did not contribute to the distribution of oral yeast species; however, age, health status, birthplace, and current geographic residence did. ${ }^{24}$ An additional culturebased study that used a variety of methods for species identification studied 323 healthy adult volunteers attending health maintenance examinations in Taiwan; $15 \%$ of subject oral cavities were colonized with yeast, $85 \%$ were Candida species. ${ }^{25}$ Other species included 2 strains of R. mucilaginosa and single strains of $C$. albidus, P. ohmeri, Prototheca, Rhodotorula, Ustilago, and $S$. cerevisiae. ${ }^{25}$

\section{Molecular Studies}

In a sentinel article, Ghannoum and colleagues, using DNA analysis of oral-rinse specimens from 20 healthy individuals, identified 74 culturable and 11 nonculturable fungal genera (101 total species) in healthy human mouths. ${ }^{12}$ Nearly half of these genera were present in only 1 of the persons sampled; 15 genera were present in 4 or more persons. Candida species ( 8 of 16 were C. albicans) were identified in $75 \%$ of persons and Cladosporium in 65\%. Aureobasidium and Saccharomyces-like species were each isolated from half of those tested. Aspergillus and Fusarium species were isolated in about one-third of specimens; Cryptococcus species were identified in $20 \%$ of individuals. ${ }^{12}$ More than $70 \%$ of identified genera are present in the natural environment, including common domestic environments. ${ }^{12,26,27}$ A notable exception is C. albicans, which does not generally survive in the environment. ${ }^{28}$

More recently, Mukherjee and colleagues used pyrosequencing to compare the "core" mycobiome (and bacteriome) in $12 \mathrm{HIV}$-infected patients to 12 matched subjects without HIV infection. ${ }^{29}$ C. albicans was the most commonly identified fungal species in both groups but was more frequently identified in subjects with HIV (83\% vs $58 \%$ ). Overall, the most common genera in those HIV-infected were Candida, Epicoccum, and Alternaria, (92\%, 33\%, and 25\% prevalence, respectively, in tested subjects), whereas Candida, Pichia, and Fusarium were most common in control subjects $\left(58 \%, 33 \%\right.$, and $33 \%$, respectively). ${ }^{29}$ These authors also presented evidence that there was an inverse relationship between core oral fungal organisms described in their report as members of the genus Pichia (Saccharomycetes yeasts whose taxonomic classification is in flux $^{\mathrm{cf.30}}$ ) and various Candida species. ${ }^{29}$ Additional experiments indicated that Pichia inhibits the growth of potential pathogens Candida, Aspergillus, and Fusarium. ${ }^{29}$

Dupuy and colleagues investigated saliva samples of 6 healthy human subjects utilizing revisions in isolation technique and sequence-based taxonomy assignments. ${ }^{13}$ Their results also demonstrated the breadth and depth of fungal genera comprising the oral mycobiota. There were several genera identified that were not present in the study of Ghannoum et al, most notably Malassezia, which was highly prevalent and abundant. Potentially pathogenic genera present in both studies include Candida, Aspergillus, Fusarium, and Cryptococcus. ${ }^{12,13}$

Other reports pointed out the challenges of interpreting data on the oral mycobiota based on molecular approaches to identification of members., ${ }^{3,27}$ These include specific technical issues; different taxonomic nomenclature among particular databases; determining at what frequency/density of identification constitutes "membership;" the number of "normal" subjects sampled; the potential for "tenacious" biofilms, gingival sulci, and periodontal pockets to prevent identification based on oral rinses; the number of nonculturable fungal species; and the potential to identify dead organisms. ${ }^{3,27}$ 


\section{DISEASE/INFECTIONS CAUSED BY ORAL MYCOBIOTA \\ Dental Disease}

Childhood dental caries, for example, may not be strictly a bacterial disease. Streptococci associated with Candida in oral biofilms may promote the invasive properties of the latter., ${ }^{3,6,7}$ Falsetta and colleagues presented evidence that $C$. albicans forms a symbiotic relationship with Streptococcus mutans such that the virulence of plaque biofilms is increased in vitro and in vivo. ${ }^{31}$ In addition, a comparison of children aged 6-12 years who did or did not have a history of dental caries revealed a significantly higher frequency of Candida species isolated from intraoral swabs and concentrated oral rinses among children with dental caries. ${ }^{32}$ Mixed infections of $C$. albicans and Peptostreptococcus micros may result in persistent endodontic infections. ${ }^{7}$

\section{Oral Candidiasis}

Among members of the oral mycobiota, Candida species cause most infections of the oral mucosa, typically in immunocompromised individuals and presumably due to local overgrowth of the organisms. ${ }^{3}$ $\mathrm{Xu}$ and Dongari-Bagtzoglou noted that "the common underlying link between all known host systemic conditions associated with oral Candida overgrowth is a functional immunodeficiency in the Th17 CD4+ cell subset." ${ }^{3}$ Changing levels in oral bacterial microbiota due to antibiotics may play an important role in Candida overgrowth and infection; however, the combination of antibiotics and local or systemic immunosuppression may be a required setting for most infections to germinate. ${ }^{3}$

In HIV-infected patients, the shift of $C$. albicans from members of the oral microbiota to opportunistic pathogen indeed appears to involve Th17 CD4+ functional depletion but also appears to involve other mechanisms, including specific binding and interactions between Candida and the HIV virus. ${ }^{33}$ Smoking is associated with increased Candida carriage and pathogenicity, likely through a variety of mechanisms. ${ }^{34}$ Also, a dysbiotic oral biota may result in an exaggerated inflammatory response to fungal opportunistic pathogens such as Candida. ${ }^{3}$ On the plus side, the rate of salivary flow and certain salivary proteins, along with other specific local responses, contribute to the innate resistance of oral mucosa to C. albicans. ${ }^{35}$ Interestingly, as opposed to virulent C. albicans, commensal Candida strains "induce regulatory immune responses maintaining tissue tolerance to the commensal fungi." 35

In addition to HIV infection, a variety of other immunocompromising conditions and local factors promote the oral pathogenesis of Candida species. These include leukemia and other oncologic disease, chemotherapy, radiation therapy, xerostomia, poor oral hygiene, malnutrition, local or systemic corticosteroid use, other immune modulating or xerogenic drugs, antibiotics, denture/retainer/mouth guard use (especially if worn during sleep), diabetes mellitus, Down syndrome, immunosenescence, and other diseases of the mouth. ${ }^{28,35-41}$ Not commonly seen in the general population (except in cases of multiple local insults, such as described in our illustrative case), oral candidiasis occurs in almost $20 \%$ of cancer patients, $9 \%-31 \%$ of AIDS patients, and $5 \%-7 \%$ of neonates. ${ }^{37}$ Fungal overgrowth typically results in accumulation of hyphae (conversion from yeast form to hyphae is critical for mucosal invasion) as well as keratin, fibrin, necrotic tissue, and other products of epithelial cell desquamation. ${ }^{35,36,38,39}$

Clinical Presentation and Diagnosis of Oral Candidiasis: Oral candidiasis may take a variety of clinical forms, which are divided into white or erythematous (red) candidiasis..$^{36,37,39}$ C. albicans is isolated in association with oral candidiasis $70 \%-80 \%$ of the time; however, other Candida species such as C. glabrata and C. tropicalis are associated with a minority of such infections. ${ }^{39}$

Pseudomembranous candidiasis (thrush) is the most common form and typically involves generally confluent white plaques on the hard and soft palate, tongue (Figure 1), buccal mucosa, oropharynx, or commonly, as seen in our illustrative case, a combination of involved regions. ${ }^{28,36,38,39}$ A distinguishing feature is the usual ability to easily wipe off the white plaques, exposing an erythematous surface. ${ }^{36-39}$ This entity may be acute or chronic. Patients are usually asymptomatic, but affected individuals may experience a sour taste, burning sensation, or tendency to bleed at the involved sites..$^{36,38}$ 


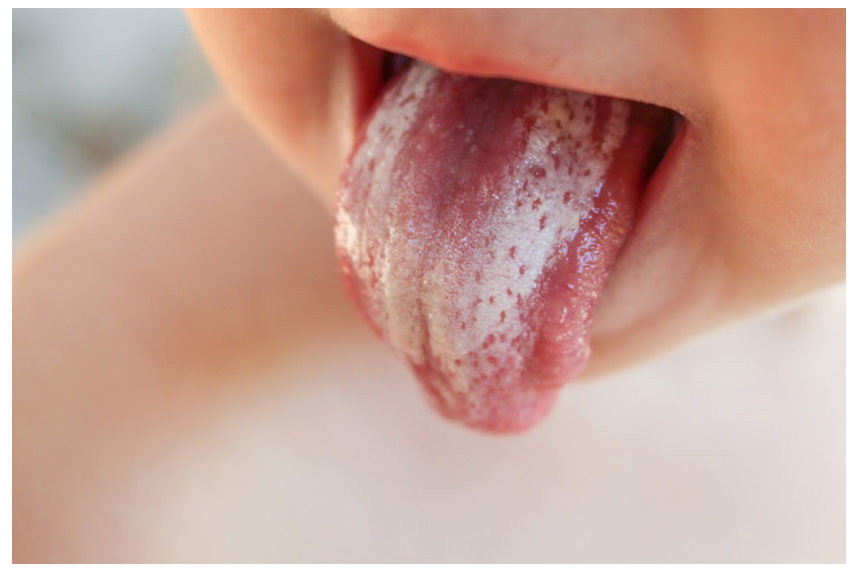

Figure 1. Infant pseudomembranous candidiasis (thrush).

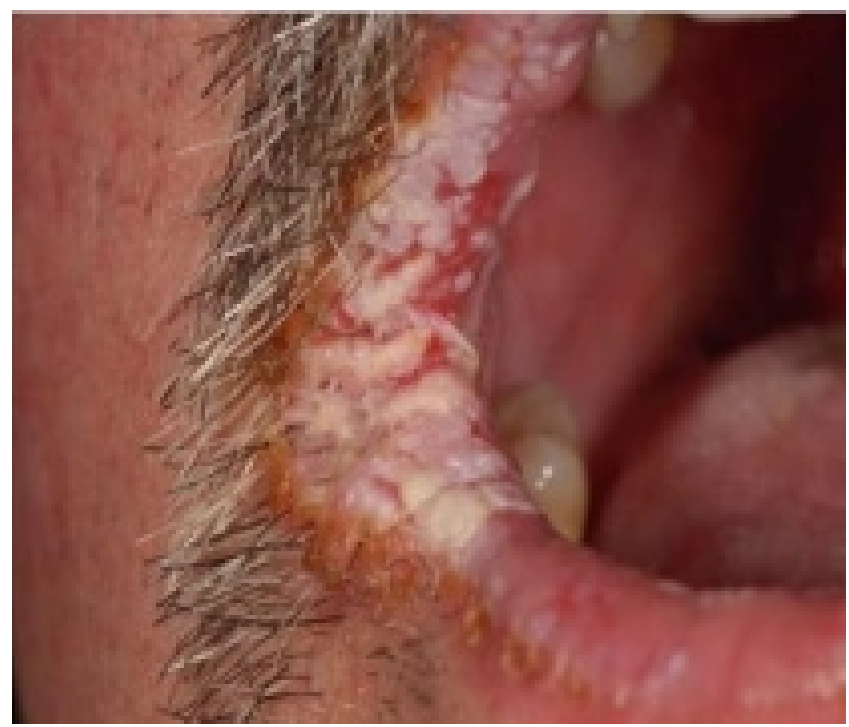

Figure 2. Hyperplastic (white) oral candidiasis on the labia, adjacent buccal mucosa and tongue. (Photograph from Williams $D$, Lewis $M$. Pathogenesis and treatment of oral candidosis. J Oral Microbiol. 2011;3(1):5771, republished with permission from David Williams and Michael Lewis per Creative Commons license.)

The other form of white oral candidiasis, the hyperplastic form, presents as "well-circumscribed, slightly elevated, white plaques most commonly adherent to the buccal mucosa," perhaps with involvement of the labial commissures or adjacent parts of the mouth (Figure 2). ${ }^{36,38}$ Lesions may be nodular or speckled in appearance and range from translucent to opaque. The manifestations of this type of candidiasis cannot be easily wiped off as with pseudomembranous candidiasis. Hyperplastic candidiasis may mimic leukoplakia and has potential for malignant change. ${ }^{36,38,39}$

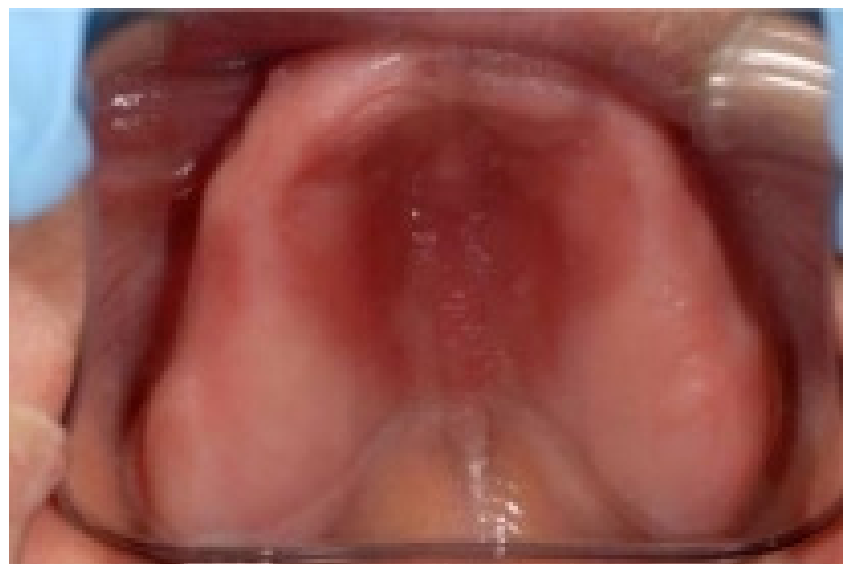

Figure 3. Acute atrophic (erythematous) candidiasis on the palate of an adult. (Photograph from Williams D, Lewis M. Pathogenesis and treatment of oral candidosis. J Oral Microbiol. 2011;3(1):5771, republished with permission from David Williams and Michael Lewis per Creative Commons license.)

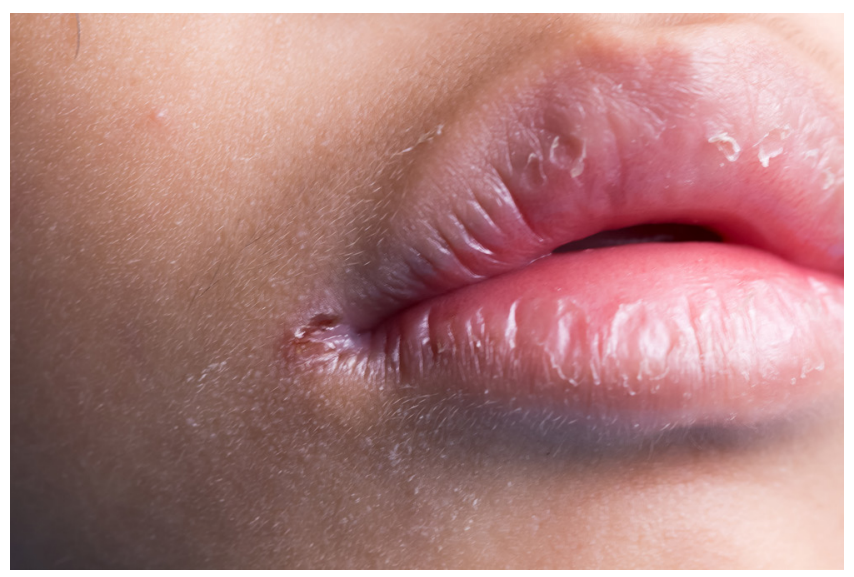

Figure 4. Angular cheilitis.

There are several forms of erythematous oral candidiasis. ${ }^{36}$ Acute atrophic candidiasis particularly occurs in HIV-infected patients and manifests as erythematous patches, most often on the palate (Figure 3 ). Other areas of the mouth may be involved, and atrophy of the lingular papillae may occur. Typical symptoms include a burning sensation in the mouth (especially with spicy foods) and/or soreness of the tongue and lip..$^{28,36,38} \mathrm{In}$ addition to the predisposing conditions noted, iron or vitamin $\mathrm{B}_{12}$ deficiency has been linked with this entity, which may occur following use of broad-spectrum antibiotics. ${ }^{36}$ 
Chronic atrophic candidiasis primarily occurs in poorly fitting denture wearers and results from Candida overgrowth (sometimes in association with bacteria) $)^{11}$ due to inhibited salivary flow — the relatively acidic and anaerobic microenvironment produced by the dentures - and the potential for continuous inoculation with the fungi and bacteria. ${ }^{36,38,39}$ Lesions are generally only in areas contacting the dentures and are generally red and swollen. This entity may be asymptomatic or result in a lateral burning sensation in the mouth. ${ }^{36}$

Angular cheilitis, also known as perlèche, may occur with denture-related candidiasis or individuals who frequently lick their lips or traumatize the corners of their mouths..$^{36,38,39}$ Individuals with redundant skin or wrinkles at the angle of the mouth may be predisposed to candidal overgrowth, and various B vitamin or iron deficiencies have been associated. Signs are usually bilateral, with red, fissured patches associated with pain or soreness observed along the commissures of the mouth (Figure 4). ${ }^{36,38,39}$ The anterior nostril region also may be affected. ${ }^{39}$ Staphylococcus aureus is often involved, along with Candida. . $^{3,38,39}$

Similarly, bacteria and Candida may be involved in the development of another erythematous oral manifestation, linear gingival erythema, which presents as a discrete red band along the gingival margin of one or more teeth. This entity may occur in progressive HIV disease; however, it can also develop in healthy children. ${ }^{36}$

In the final form of erythematous oral candidiasis, median rhomboid glossitis (central papillary atrophy), the association with chronic Candida infection may not be completely causative. ${ }^{39}$ It is quite rare and appears as a generally asymptomatic, smooth, and glossy rhomboidshaped red patch or plaque in the center of the dorsal tongue (may involve a developmental abnormality), anterior to the circumvallate papillae. It is associated with smoking and inhaled corticosteroids..$^{36,38,39}$

Chronic mucocutaneous candidiasis is an additional variant of oral candidiasis. It is a less well-defined disorder, consisting of several of the aforementioned forms of candidiasis in association with chronic skin and nail lesions that are generally unresponsive to topical therapy. It may begin in childhood, involve single-gene mutations, and is typically associated with abnormalities of the endocrine system. ${ }^{15,28,36}$ Significant disfigurement and social rejection may result from the clinical manifestations. ${ }^{28}$ Smokers may present with a chronic multifocal candidiasis without other obvious risk factors. ${ }^{36}$ Cheilocandidiasis is an ulcerating lip lesion, typically on the lower vermilion border. ${ }^{36}$

Whether Candida species are related to noninfectious oral disease requires further investigation. Recently, virulence factors of Candida species isolated from the mouth of patients with oral squamous cell carcinoma were more pronounced than from species isolated from mouths of patients with lichen planus, chronic candidiasis, and asymptomatic carriers of Candida ${ }^{42}$

Diagnosis of these previously described oral Candida disorders is made by typical history and appearance and may be confirmed by fungal wet mount or stained smear, culture, or biopsy. ${ }^{36,38,39}$ The differential diagnosis is rather broad, with white lesions needing to be distinguished from simply the presence of milk or other white food, other oral fungal disease, local trauma or burns, leukoplakia, nutritional deficiency, chronic immunobullous diseases, lichen planus, mucositis of chemotherapy, and primary syphilis. In addition to trauma, geographic tongue, pernicious anemia, zinc deficiency, and lichen planus, erythematous oral candidiasis is to be distinguished from systemic lupus erythematous and erythema multiforme. ${ }^{36-38}$ Diagnosis is usually made clinically; however, fungal smear or culture, and possibly oral biopsy, may be required. ${ }^{36,38,39}$ Follow-up of chronic hyperplastic candidiasis, including serial biopsy as necessary, is important to rule out leukoplakia and to monitor for dysplastic features. ${ }^{39}$

\section{Treatment and Prevention of Oral Candidiasis:} Treatment of oral candidiasis should be based on type of manifestation, immune status of the host, and degree of involvement or lack of response to previous therapy. ${ }^{36}$ The breadth of treatment options and details are well covered in the article by Millsop and Fazel, to which the reader is referred. ${ }^{36}$ Commonly used treatments are listed in Table 1.

In all cases, good oral and denture hygiene and removal of the underlying predisposing factor(s), when possible, are very important. This includes daily flossing and twice daily brushing of teeth and tongue, regular dental care, treatment of xerostomia with 
Table 1. Common Treatment of Oral Candidiasis ${ }^{36-39}$

\begin{tabular}{|c|c|c|c|}
\hline Disease & Treatment & Alternative & Most common side effects \\
\hline Infant thrush & $\begin{array}{l}\text { Nystatin oral suspension } \\
(100,000 \mathrm{U} / \mathrm{mL}), 1 \mathrm{~mL} \text { into } \\
\text { each cheek } 4 \text { times a day } \\
\text { until } 2 \text { days past resolution }\end{array}$ & $\begin{array}{l}\text { Oral fluconazole (in age } 6 \\
\text { months or older) } 6 \mathrm{mg} / \mathrm{kg} \text { on } \\
\text { day } 1, \text { followed by } 3 \mathrm{mg} / \mathrm{kg} \\
\text { daily } \times \text { at least } 14 \text { days }\end{array}$ & $\begin{array}{l}\text { Nystatin: minimal; skin irritation } \\
\text { Fluconazole: nausea/vomiting }\end{array}$ \\
\hline Childhood thrush & $\begin{array}{l}\text { Nystatin oral suspension } \\
(100,000 \mathrm{U} / \mathrm{mL}), 4-6 \mathrm{~mL} \text { hold } \\
\text { and swallow } 4 \text { times a day } \\
\text { until } 2 \text { days past resolution } \\
\text { (at least } 7-14 \text { days if HIV) }\end{array}$ & $\begin{array}{l}\text { Non-HIV: oral fluconazole as } \\
\text { above; HIV: oral fluconazole } \\
3-6 \mathrm{mg} / \mathrm{kg} \text { daily } \times 7-14 \text { days } \\
\text { or } \\
\text { In age } 3 \text { years or older: } \\
\text { clotrimazole } 10 \mathrm{mg} \text { lozenge } \\
\text { dissolved slowly } 5 \text { times a } \\
\text { day } \times 14 \text { days }\end{array}$ & $\begin{array}{l}\text { Nystatin: as above } \\
\text { Fluconazole: nausea/vomiting, } \\
\text { headache } \\
\text { Clotrimazole: nausea/vomiting }\end{array}$ \\
\hline $\begin{array}{l}\text { Adult oral candidiasis, } \\
\text { most forms }\end{array}$ & Nystatin, as above & $\begin{array}{l}\text { Clotrimazole, as above } \\
\text { or } \\
\text { Oral fluconazole } 200 \mathrm{mg} \text { on } \\
\text { day } 1 \text {, then } 100-200 \mathrm{mg} \text { daily } \\
\times 7-14 \text { days }\end{array}$ & $\begin{array}{l}\text { Nystatin*: as above } \\
\text { Clotrimazole*: as above } \\
\text { Fluconazole*: as above }\end{array}$ \\
\hline Angular cheilitis & $\begin{array}{l}\text { Nystatin with or without } \\
\text { triamcinolone applied } 2 \\
\text { times a day } \times 14 \text { days }\end{array}$ & & Skin irritation \\
\hline
\end{tabular}

*Pregnancy category $C$.

frequent water and/or ice chips or sugarless lozenge intake, control of diabetes, and limitation of topical or systemic corticosteroid and antibiotic use when possible. ${ }^{36}$ Dentures may be soaked for 30 minutes twice weekly, preferably daily, with white vinegar, chlorhexidine gluconate $2 \%$ suspension, or a solution of 1 part household bleach mixed with 10 parts water, followed by thorough rinse and air drying. ${ }^{36,39}$ Mouth guards should be well ventilated when stored, not shared, and washed with warm, soapy water after use. ${ }^{41}$

For infant thrush, the mainstay of treatment remains nystatin oral suspension $(100,000 \mathrm{U} / \mathrm{mL}), 1 \mathrm{~mL}$ into each cheek 4 times a day until 2 days past resolution. Oral fluconazole is an alternative for those 6 months old or older: $6 \mathrm{mg} / \mathrm{kg}$ on day 1 , followed by $3 \mathrm{mg} / \mathrm{kg}$ daily for at least 14 days. Infant pacifiers and bottle nipples should be boiled; in breastfed babies, the mothers areolae may be treated with topical antifungals such as nystatin for the duration of treatment of the infant. ${ }^{37}$

For oropharyngeal candidiasis prophylaxis, oral fluconazole or itraconazole are more effective than placebo in people receiving chemotherapy or radiation for cancer, and daily or weekly fluconazole or itraconazole prophylaxis is effective in persons with HIV infection. ${ }^{43}$ Topical clotrimazole lozenges and miconazole slow-release tablets, or single-dose (750 mg) fluconazole, may be as effective as standard oral agents for symptom reduction in those with $\mathrm{HIV}^{43}$ Fluconazole may be used prophylactically in immunocompromised infants and children. ${ }^{43}$

When treating oral candidiasis in pregnant women, prescribers should take into account the pregnancy risk categories of available medications.

\section{Other Oral Fungal Infections}

Other invasive fungal organisms that have been identified as potential members of the oral mycobiota may cause oral disease, if rarely. C. neoformans may produce oral lesions in the form of superficial ulcerations, nodules, or granulomas. These lesions may mimic oral carcinoma. ${ }^{39}$ Aspergillus species may cause palatal or other oral disease, which often appear as black or yellow necrotic lesions following progression from infection in the maxillary sinuses. ${ }^{39}$ Similarly, saprophytic Mucoraceae has been cultured 
from healthy oral cavities and may cause necrosis or ulceration of the palate in immunocompromised individuals via extension from paranasal infection. ${ }^{39}$ Geotrichum is an uncommon oral mycobiota member and has been reported to cause oral disease in immunocompromised patients or diabetics. ${ }^{44}$

\section{IMPORTANCE OF ORAL MYCOBIOTA BEYOND THE MOUTH}

$\mathrm{Xu}$ and Dongari-Bagtzoglou hypothesized that pathogenic fungi such as Cryptococcus, Aspergillus, and Fusarium, if indeed common residents of the oral cavity, may normally be "under continuous surveillance and control by healthy immune systems." Ghannoum and colleagues agreed and questioned whether harboring potential fungal pathogens in the oral cavity could predispose a susceptible host to an opportunistic infection elsewhere. ${ }^{12}$ Microaspiration of microbiome organisms from the upper airway is likely the chief source of microorganisms in the healthy lung; however, the composition of organisms differs from that seen in oral wash specimens. ${ }^{27}$

Known interactions between C. albicans and streptococci also may promote synergistic colonization in the gastrointestinal tract. ${ }^{3}$ Oral candidiasis may spread beyond the mouth to cause esophageal or gastric candidiasis. ${ }^{37}$ There is evidence in HIV-infected patients that mycobiome profiles in the respiratory and gastrointestinal tracts are similar to that in the mouth. ${ }^{45,46}$ Whether or not there are meaningful associations with fungi such as Candida, or Saccharomyces, on such things as Crohn's disease remains to be confirmed, let alone whether or not the source of these fungi is the oral cavity. ${ }^{27}$ In addition, there is evidence, at least for gut Candida, that these species can influence immunity at other areas of the body..$^{15}$ Candida has been postulated to potentially promote tumor formation via its properties of adhesion, biofilm production, and protease and hemolytic activity, in addition to being detected in samples of adenomas (with unclear associations). ${ }^{47}$ Additionally, as an example, a recent association (directionality unknown) has been made between oral Candida residence and colony counts and psoriasis. ${ }^{48}$

Finally, in consideration of recent press articles, Candida auris, an emerging, often multidrug-resistant, invasive, difficult-to-identify pathogen, can apparently colonize the oropharynx and mouth, although to a much lesser extent than other nonsterile sites. ${ }^{49,50}$ Implications are unclear, however, this fungus illustrates the importance of good antifungal stewardship (even in treatment of minor oral disease), not only to reduce cost and toxicity but to reduce pressure on emergence of resistance. ${ }^{51}$

\section{CONCLUSIONS}

The oral mycobiome is complex, interactive, and involves extensive biofilm formation. Candida is a microorganism frequently colonized in the human mouth, and several other pathogenic fungi appear to be oral residents in some individuals. Protean oral disease is commonly caused or co-caused by Candida species and, rarely, by other fungi. Prevention is largely dependent on maintaining good oral hygiene and avoiding unnecessary corticosteroids and antibiotics. Clinical treatments range from oral suspensions or lozenges to oral tablets. As Hager and Ghannoum recently emphasized, ${ }^{45}$ while much is known about the potential for oral bacteria to ultimately infect or affect other areas of the body, much remains to be investigated regarding the importance of oral fungi such as Candida or Cryptococcus as agents of more disseminated disease.

\section{Patient-Friendly Recap}

- Although more well known for harboring bacteria, the normal human mouth also contains many fungal microorganisms, some of which can cause infection.

- The most common fungal disease of the mouth is called "thrush." It occurs in infants, children, and adults and is usually treated with oral suspensions, lozenges, or tablets.

- The best approach to preventing oral fungal disease is to consistently maintain oral hygiene, especially if using dentures or mouth guards, and avoiding unnecessary steroid medications and antibiotics.

\section{Conflicts of Interest}

None.

\section{References}

1. Zhang Y, Wang X, Li H, Ni C, Du Z, Yan, F. Human oral microbiota and its modulation for oral health. Biomed Pharmacother. 2018;99:883-93. CrossRef

2. Verma D, Garg PK, Dubey AK. Insights into the human oral microbiome. Arch Microbiol. 2018;200:525-40. $\underline{\text { CrossRef }}$ 
3. Xu H, Dongari-Bagtzoglou A. Shaping the oral mycobiota: interactions of opportunistic fungi with oral bacteria and the host. Curr Opin Microbiol. 2015;26:65-70. CrossRef

4. Wade WG. The oral microbiome in health and disease. Pharmacol Res. 2013;69:137-43. CrossRef

5. Chevalier M, Ranque S, Prêcheur I. Oral fungal-bacterial biofilm models in vitro: a review. Med Mycol. 2018;56:653-67. CrossRef

6. Marsh PD, Zaura E. Dental biofilm: ecological interactions in health and disease. J Clin Periodontol. 2017;44 Suppl 18:S12-22. CrossRef

7. Shirtliff ME, Peters BM, Jabra-Rizk MA. Cross-kingdom interactions: Candida albicans and bacteria. FEMS Microbiol Lett. 2009;299:1-8. CrossRef

8. Demmitt BA, Corley RP, Huibregtse BM, et al. Genetic influences on the human oral microbiome. BMC Genomics. 2107;18:659. CrossRef

9. Monteiro-da-Silva F, Araujo R, Sampaio-Maia B. Interindividual variability and intraindividual stability of oral fungal microbiota over time. Med Mycol. 2014;52:496-503. CrossRef

10. Mira A, Simon-Soro A, Curtis MA. Role of microbial communities in the pathogenesis of periodontal diseases and caries. J Clin Periodontol. 2017;44 Suppl 18:S23-38. CrossRef

11. O'Donnell LE, Robertson D, Nile CJ, et al. The oral microbiota of denture wearers is influenced by levels of natural dentition. PLoS One. 2015;10(9):e0137717. CrossRef

12. Ghannoum MA, Jurevic RJ, Mukherjee PK, et al. Characterization of the oral fungal microbiome (mycobiome) in healthy individuals. PLoS Pathog. 2010;6(1):e1000713. CrossRef

13. Dupuy AK, David MS, Li L, et al. Redefining the human oral mycobiome with improved practices in amplicon-based taxonomy: discovery of Malassezia as a prominent commensal. PLoS One. 2014;9(3):e90899. CrossRef

14. Moissl-Eichinger C, Pausan M, Taffner J, Berg G, Bang C, Schmitz RA. Archaea are interactive components of complex microbiomes. Trends Microbiol. 2018;26:70-85. CrossRef

15. Underhill DM, Iliev ID. The mycobiota: interactions between commensal fungi and the host immune system. Nat Rev Immunol. 2014;14:405-16. $\underline{\text { CrossRef }}$

16. Carroll KC, Hobden JA. Normal human microbiota. In: Carroll KC, Morse SA, Mietzner T, Miller S (eds). Jawetz, Melnick \& Adelberg's Medical Microbiology, 27th Edition. New York, NY: McGraw-Hill Education, 2016, pp. 169-177.

17. DiBardino DM, Wunderink RG. Aspiration pneumonia: a review of modern trends. J Crit Care. 2015;30:40-8. CrossRef

18. Bracci PM. Oral health and the oral microbiome in pancreatic cancer: an overview of epidemiological studies. Cancer J. 2017;23:310-4. CrossRef

19. Flemer B, Warren RD, Barrett MP, et al. The oral microbiota in colorectal cancer is distinctive and predictive. Gut. 2018;67:1454-63. CrossRef

20. Ward TL, Knights D, Gale CA. Infant fungal communities: current knowledge and research opportunities. BMC Med. 2017;15(1):30. $\underline{\text { CrossRef }}$

21. Mueller NT, Bakacs E, Combellick J, Grigoryan Z, DominguezBello MG. The infant microbiota development: mom matters. Trends Mol Med. 2015;21:109-17. CrossRef
22. Janus MM, Crielaard W, Volgenant CMC, van der Veen $\mathrm{MH}$, Brandt BW, Krom BP. Candida albicans alters the bacterial microbiome of early in vitro oral biofilms. J Oral Microbiol. 2017;9(1):1270613. CrossRef

23. Stecksén-Blicks C, Granström E, Silfverdal SA, West CE. Prevalence of oral Candida in the first year of life. Mycoses. 2015;58:550-6. CrossRef

24. Wang H, Xu J, Guo H, et al. Patterns of human oral yeast species distribution on Hainan Island in China. Mycopathologia. 2013;176:359-68. CrossRef

25. Yang YL, Leaw SN, Wang AH, Chen HT, Cheng WT, Lo HJ. Characterization of yeasts colonizing in healthy individuals. Med Mycol. 2011;49:103-6. CrossRef

26. Baumgardner DJ. Disease-causing fungi in homes and yards in the Midwestern United States. J Patient Cent Res Rev. 2016;3:99-110. CrossRef

27. Limon JJ, Skalski JH, Underhill DM. Commensal fungi in health and disease. Cell Host Microbe. 2017;22:156-65. CrossRef

28. Reiss E, Shadomy HJ, Lyon GM III. Candidiasis and less common yeast genera. In: Fundamental Medical Mycology. Hoboken, NJ: Wiley-Blackwell, 2012, pp. 249-301. CrossRef

29. Mukherjee PK, Chandra J, Retuerto M, et al. Oral mycobiome analysis of HIV-infected patients: identification of Pichia as an antagonist of opportunistic fungi. PLoS Pathog. 2014;10(3):e1003996. CrossRef

30. Kurtzman CP, Robnett CJ, Basehoar-Powers E. Phylogenetic relationships among species of Pichia, Issatchenkia and Williopsis determined from multigene sequence analysis, and the proposal of Barnettozyma gen. nov., Lindnera gen. nov. and Wickerhamomyces gen. nov. FEMS Yeast Res. 2008;8:939-54. CrossRef

31. Falsetta ML, Klein MI, Colonne PM, et al. Symbiotic relationship between Streptococcus mutans and Candida albicans synergizes virulence of plaque biofilms in vivo. Infect Immun. 2014;82:1968-81. CrossRef

32. Raja M, Hannan A, Ali K. Association of oral candidal carriage with dental caries in children. Caries Res. 2010;44:272-6. CrossRef

33. Cassone A, Cauda R. Candida and candidiasis in HIV-infected patients: where commensalism, opportunistic behavior and frank pathogenicity lose their borders. AIDS. 2012;26:1457-72. CrossRef

34. Soysa NS, Ellepola AN. The impact of cigarette/tobacco smoking on oral candidosis: an overview. Oral Dis. 2005;11:268-73. CrossRef

35. Feller L, Khammissa RAG, Chandran R, Altini M, Lemmer J. Oral candidosis in relation to oral immunity. J Oral Path Med. 2014;43:563-9. CrossRef

36. Millsop JW, Fazel N. Oral candidiasis. Clin Dermatol. 2016;34:487-94. CrossRef

37. Silk H. Diseases of the mouth. Prim Care. 2014;41:75-90. CrossRef

38. Stoopler ET, Sollecito TP. Oral mucosal diseases: evaluation and management. Med Clin North Am. 2014;98:1323-52. CrossRef

39. Muzyka BC, Epifanio RN. Update on oral fungal infections. Dent Clin North Am. 2013;57:561-81. CrossRef

40. Al Groosh D, Roudsari GB, Moles DR, Ready D, Noar JH, Pratten J. The prevalence of opportunistic pathogens associated with intraoral implants. Lett Appl Microbiol. 2011;52:501-5. CrossRef 
41. Face \& Jaw Surgery Center. Cleaning mouth guards to avoid mouth disease. Posted 2012 Nov 7. https://www. faceandjawsurgery.com/cleaning-mouth-guards-to-avoidmouth-disease/ Accessed February 26, 2019.

42. Castillo GDV, Blanc SL, Sotomayor CE, Azcurra AI. Study of virulence factor of Candida species in oral lesions and its association with potentially malignant and malignant lesions. Arch Oral Biol. 2018;91:35-41. CrossRef

43. Pankhurst CL. Candidiasis (oropharyngeal). BMJ Clin Evid. 2013;11:1304.

44. Bonifaz A, Vázquez-González D, Macías B, et al. Oral geotrichosis; report of 12 cases. J Oral Sci. 2010;52:477-83. CrossRef

45. Hager CL, Ghannoum MA. The mycobiome in HIV. Curr Opin HIV AIDS. 2018;13:69-72. CrossRef

46. Cui L, Lucht L, Tipton L, et al. Topographic diversity of the respiratory tract mycobiome and alteration in HIV and lung disease. Am J Respir Crit Care Med. 2015;191:932-42. $\underline{\text { CrossRef }}$
47. Klimesova K, Jiraskova Zakostelska Z, Tlaskalova-Hogenova H. Oral bacterial and fungal microbiome impacts colorectal carcinogenesis. Front Microbiol. 2018;9:774. CrossRef

48. Lesan S, Toosi R, Aliakbarzadeh R, et al. Oral Candida colonization and plaque type psoriasis: Is there any relationship? J Invest Clin Dent. 2018;9(3):e12335. CrossRef

49. Cortegiani A, Misseri G, Fasciana T, Giammanco A, Giarratano A, Chowdhary A. Epidemiology, clinical characteristics, resistance, and treatment of infections by Candida auris. J Intensive Care. 2018;6:69. CrossRef

50. Centers for Disease Control and Prevention. Candida auris. Last reviewed 2019 Sep 9. www.cdc.gov/fungal/candida-auris. Accessed September 24, 2019.

51. Pfaller MA, Castanheira M. Nosocomial candidiasis: antifungal stewardship and the importance of rapid diagnosis. Med Mycol. 2016;54:1-22. $\underline{\text { CrossRef }}$

(C) 2019 Aurora Health Care, Inc.

\section{CME/MOC Accreditation and Credit Designation Statements}

Advocate Aurora Health is accredited by the Accreditation Council for Continuing Medical Education (ACCME) to provide continuing medical education for physicians. Aurora Health Care designates this journal-based CME article for a maximum of 1.00 AMA PRA Category 1 credit $^{\text {TM }}$. Physicians should claim only the credit commensurate with the extent of their participation in the activity.

Successful completion of this CME activity enables the participant to earn up to 1.0 MOC points in the American Board of Internal Medicine's (ABIM) Maintenance of Certification (MOC) program. Participants will earn MOC points equivalent to the amount of CME credits claimed for the activity. It is the CME activity provider's responsibility to submit participant completion information to ACCME for the purpose of granting ABIM MOC credit.

To earn CME credit for this article, visit cme.advocateaurorahealth.org/content/ oral-fungal-microbiota-thrush-and-beyond to access and complete the online quiz. 